\title{
IMPORTANT INFORMATION FOR SUBSCRIBERS
}

\author{
HORIZONS \\ The Journal of the College Theology Society
}

The College Theology Society is pleased to announce that from 2013 Horizons will be published by Cambridge University Press.

The journal will be available in a fully searchable electronic format in addition to print. From 2013 all library subscriptions will include online access back to Volume 31 (2004) in addition to print, or libraries have the option to purchase an online-only subscription, which will likewise include access back to Volume 31 (2004).

Earlier volumes will be made available online through the Cambridge Journals Digital Archive.

If you are a current subscriber, you will automatically receive an invitation to renew from Cambridge University Press.

If you are not a current subscriber and would like further information please visit journals.cambridge.org/hor, or contact us by email at subscriptions newyork@cambridge.org or phone at (845) 3537500.

All queries about 2012 subscriptions to Horizons should be addressed to the editorial office at horizons@villanova.edu. 